\title{
Distúrbios do sono durante a pandemia de COVID-19
}

\author{
Sleep disorders during the COVID-19 pandemic \\ Distúrbios do sono durante a pandemia de COVID-19
}

Questões de saúde mental se tornaram uma preocupação global durante a pandemia de coronavírus (COVID-19). Distúrbios do sono são os principais problemas de saúde mental, associados ao aumento dos estressores psicossociais. O sono é uma atividade fisiológica essencial para o bem-estar físico e mental e para qualidade de vida. A quebra do ciclo normal de sono pode levar ao descanso insuficiente e estado prolongado de alerta, aumentando o risco de insônia, pesadelos, sonolência excessiva diurna e fadiga. Estudos recentes mostraram que a insônia afeta $34 \%$ dos profissionais de saúde que, tradicionalmente, estão associados a comorbidades como distúrbios psiquiátricos. Circunstâncias estressantes graves como depressão, ansiedade, trauma, baixa condição socioeconômica, vida urbana agitada, maior uso de tecnologia e mídias sociais implicam em fatores de risco potenciais para distúrbios do sono. Essa situação se agrava nas atuais circunstâncias, pois há vários estressores psicológicos. O número de pessoas com transtornos mentais, de forma geral, tende a aumentar, assim como o de pessoas com transtornos do sono ${ }^{1}$.

Em uma grande revisão, foi detectado que os distúrbios do sono são problemas significativos de saúde mental associados a este período de pandemia. Os resultados sugerem alta carga de distúrbios do sono em diferentes grupos populacionais. Os principais fatores associados aos distúrbios do sono em países desenvolvidos ${ }^{2}$ em pessoas do gênero feminino, na população mais jovem e nos profissionais de saúde foram estressores relacionados ao COVID-19.

Os profissionais de saúde mental devem realizar uma avaliação do componente psicossocial nas insônias detectando seus fatores desencadeadores e perpetuantes. Doenças e perdas familiares podem ser um fator desencadeante, porém, ao longo do tempo, a insônia pode se descolar do fator gerador e se perpetuar por meio de pensamentos negativos e hábitos ruins de higiene de sono ${ }^{3}$.
Todos os pacientes que entram em contato com os centros de saúde devem ser examinados, e aqueles com diagnóstico de qualquer forma de insônia devem ser encaminhados aos recursos e estratégias apropriados. Como os profissionais de saúde relataram carga maior de insônia, devem estar disponíveis intervenções específicas, projetadas para abordar os problemas em unidades de saúde. A maioria dos profissionais de saúde está sobrecarregada. Se a saúde e o bem-estar não forem garantidos, a capacidade de trabalhar ficará ainda mais comprometida, impondo uma situação severa ao frágil sistema de saúde atual ${ }^{4}$.

A terapia cognitivo-comportamental é o tratamento de escolha para a insônia. Se a orientação presencial não for possível, devido às medidas de distanciamento social para prevenir a propagação do vírus, intervenções semelhantes podem ser realizadas usando as plataformas virtuais. Por poder ser administrada pela Internet, pelo computador ou celular, a terapia cognitivo-comportamental foi considerada uma alternativa eficaz e viável no contexto atual. Paralelamente, outras vias de telepsiquiatria, como clínicas virtuais, psicoterapias administradas remotamente, psicoeducação, linhas de escuta e orientação 24 horas por dia, sete dias por semana e monitoramento digital também podem ser exploradas ${ }^{4,5}$.

Para áreas com baixa conexão de Internet ou para indivíduos que não estão acostumados aos formatos modernos de intervenção, os folhetos ou manuais de orientação podem ser uma alternativa eficaz, mas podem reduzir a padronização do atendimento, o controle de qualidade e a utilização ideal dos recursos 5 .

Exercícios e intervenções dietéticas estão associados à melhora da qualidade do sono. Dietas com baixo teor de gordura e maior quantidade de exercícios apresentaram bons resultados, alterando as vias metabólicas. Pesquisas de intervenções futuras devem se concentrar em como as intervenções baseadas no estilo de vida podem impactar a 
qualidade do sono e a saúde mental geral em diferentes populações em risco. É fundamental avaliar os fatores de risco e a proteção, que podem ser usados para desenvolver programas de promoção da saúde mental, que potencialmente previnam distúrbios do sono entre indivíduos vulneráveis. $\mathrm{O}$ escopo das intervenções digitais, grupos de apoio, serviços de saúde mental baseados na comunidade, programas de autogerenciamento e recursos públicos de saúde mental devem ser avaliados para promovê-la e prevenir distúrbios do sono nas populações. Em meio a esse contexto pandêmico, além do controle de infecções ${ }^{5}$, os problemas de saúde mental estão se tornando uma preocupação crescente.

\section{REFERÊNCIAS}

1. Preti E, Di Mattei V, Perego G, Ferrari F, Mazzetti M, Taranto P, et al. The psychological impact of epidemic and pandemic outbreaks on healthcare workers: rapid review of the evidence. Curr Psychiatry Rep. 2020;22(8):43. doi: 10.1007/ s11920-020-01166-z.

2. Hossain MM, Sultana A, Purihit N. Mental health outcomes of quarantine and isolation for infection prevention: a systematic umbrella review of the global evidence. Epidemiol Health. 2020;42:e2020038. doi: 10.31234/osf.io/dz5v2.

3. Pinto MCR, Alves RC. Componente psicossocial nas insônias: fatores desencadeadores e perpetuantes. In: Pinto LR Jr. Diretrizes para o diagnóstico e tratamento da insônia. Rio de Janeiro: Elsevier; 2009.

4. Torales J, O'Higgins M, Castaldelli-Maia JM, Ventriglio A. The outbreak of COVID- 19 coronavirus and its impact on global mental health. Int J Soc Psychiatry. 2020;66(4):317-20. doi:10.1177/0020764020915212.

5. Rossi R, Socci V, Talevi D, Mensi S, Niolu C, Pacitti F, et al. COVID-19 Pandemic and lockdown measures impact on mental health among the general population in Italy. Front Psychiatry. 2020;11:790. doi:10.3389/fpsyt.2020.00790.

Susana Lerosa Telles

Pontifícia Universidade Católica de São Paulo (PUC-SP) - São Paulo (SP), Brasil. https://orcid.org/0000-0002-4492-8666

Mariana Callil Voos

Pontifícia Universidade Católica de São Paulo (PUC-SP) - São Paulo (SP), Brasil. bttps://orcid.org/0000-0001-6252-7287 